\title{
Lowering of intraocular pressure in the untreated eye after the use of topical steroids
}

\author{
S. N. DAS AND R. A. HITGHINGS \\ Moorfields Eye Hospital, City Road, London E.C.I
}

The effect of steroids on intraocular pressure (IOP) has been interesting to ophthalmologists since reports of the effect of ACTH (Stern, 1953; François, 1954) and of topical steroids (Linnér I959, a, b; Goldmann, I 962) were first published. It has been suggested that steroids act on the trabecular meshwork at the angle of the anterior chamber (Goldmann, I 962 ; Becker and Mills, I 963), probably by causing mucopolysaccharide deposition, and thereby reducing the pore size (Armaly, 1965; Lieb, 1963) and consequently the outflow facility of aqueous humour.

The hereditary nature of chronic simple glaucoma (Miller and Paterson, 1962; Armaly, I $967 \mathrm{a}$ ) and of the steroid-induced rise in IOP (Armaly, I $966 \mathrm{a}, \mathrm{b}$ ) are now well established. The sharing of similar genetic determinants by diabetes mellitus and chronic simple glaucoma has also been demonstrated (Armaly, 1967 b).

In this investigation the short-term and long-term effects on both eyes of the administration of topical steroids to one (the treated) eye have been studied. The effect of topical steroids on the treated eye is well documented (Armaly I 963 a, b; Becker and Mills, 1963; Levene, Wigdor, Edelstein. and Baum, I967; Ramsell, Trillwood, and Draper, I967), but that on the untreated eye has received little attention.

\section{Methods and material}

I. SHORT-TERM EFFECTS

Thirty patients were examined over a $2 \frac{1}{2} \mathrm{hr}$ period. There were 26 cases of medically-controlled chronic simple glaucoma, three known steroid responders, and one case of simple ocular hypertension.

Both eyes of each patient were anaesthetized with Novesine ( 0.4 per cent.) and fluorescein mixture. The IOP was measured with a Goldmann applanation tonometer on a Haag-Streit goo slit lamp.

Gutt. dexamethasone (0.05 per cent.) were instilled into one eye only of each patient. The eye to be treated was chosen by random selection throughout this study. The IOP was measured in both eyes $30 \mathrm{~min}$. later. A further instillation of gutt. dexamethasone was then made into the same eye, and after another $30 \mathrm{~min}$. the IOP was measured for a period of $2 \frac{1}{2} \mathrm{hrs}$.

\section{LONG-TERM EFFECTS}

55 patients were examined every week for 6 weeks. There were forty cases of medically-controlled chronic simple glaucoma and fifteen of simple ocular hypertension. None of these patients had had any previous intraocular surgery. 
The IOP was measured in both eyes of each patient using the same technique as in the first series. The nature of the project was explained so that the patients could be expected to follow their instructions correctly (Spaeth, 1970). They were asked to instil gutt. dexamethasone ( 0.5 per cent.) three times daily into one eye only. Patients who were having antiglaucoma therapy before this trial were instructed to continue with their regime as usual in addition to the dexamethasone drops. They were examined every week for 6 weeks at the same time of day to allow for diurnal variation (Lawton Smith, 1962).

To avoid observer bias the IOP was measured in both eyes before it was known which eye had been treated with dexamethasone.

\section{Results}

\section{SHORT TERM}

The initial IOP was compared with that recorded after $2 \frac{1}{2} \mathrm{hrs}$ steroid instillation in both eyes for each patient. A paired data programme was used to analyse the results in the computer. Students' " $t$ " test was done.

There was no significant change in IOP over the $2 \frac{1}{2} \mathrm{hrs}$ period in either eye.

\section{LONG TERM}

The initial IOP for each eye was compared with that recorded each week for the same eye.

Out of 55 patients, twenty were found to have a rise of $6 \mathrm{~mm} . \mathrm{Hg}$ or more in the treated eye during the 6 weeks of the trial. In these patients, designated "responders" (Armaly, I965), the IOP rose significantly in both eyes (Table).

The other 35 patients were designated "non-responders". In this group the IOP showed little change in the first 4 weeks but did rise significantly in the $5^{\text {th }}$ and 6 th weeks in the treated eye. There was, however, a gradual and significant fall in the IOP in the untreated eye beginning from the $3^{\text {rd }}$ week (Table).

Table Results in responders and non-responders in Series II

\begin{tabular}{|c|c|c|c|c|c|c|c|c|c|}
\hline \multirow{2}{*}{\multicolumn{2}{|c|}{$\frac{\text { Group }}{\text { Eye }}$}} & \multicolumn{4}{|c|}{ Responders } & \multicolumn{4}{|c|}{ Non-responders } \\
\hline & & \multicolumn{2}{|l|}{ Treated } & \multicolumn{2}{|c|}{ Untreated } & \multicolumn{2}{|l|}{ Treated } & \multicolumn{2}{|c|}{ Untreated } \\
\hline $\operatorname{IOP}(n$ & $n m . H g)$ & Change & $P$ & Change & $P$ & Change & $P$ & Change & $P$ \\
\hline Week & $\begin{array}{l}\text { I } \\
2 \\
3\end{array}$ & $\begin{array}{l}+6.1 \\
+8.2 \\
+11.6\end{array}$ & $\begin{array}{l}<0.001 \\
<0.001 \\
<0.001\end{array}$ & $\begin{array}{r}+2 \cdot 5 \\
+3 \cdot 2 \\
+3 \cdot 2\end{array}$ & $\begin{array}{l}<0.05 \\
<0.01 \\
<0.0 I\end{array}$ & $\begin{array}{r}-0.5 \\
+0.3 \\
+1.3\end{array}$ & $\begin{array}{l}\text { Nil } \\
\text { Nil } \\
<0.02\end{array}$ & $\begin{array}{l}-0.9 \\
-I \cdot 4 \\
-I \cdot 9\end{array}$ & $\begin{array}{l}\text { Nil } \\
<0.0 \mathrm{I} \\
<0.00 \mathrm{I}\end{array}$ \\
\hline
\end{tabular}

\section{Discussion}

The most significant finding was that the application of topical steroids to one eye can cause a fall in the IOP in the other eye in the "non-responder" group. This important fact appears to have been overlooked by most authors. Armaly (1966) noted a fall in IOP $(0.9 \mathrm{~mm} . \mathrm{Hg})$ in the untreated eye in normal patients, but found it to be statistically insignificant.

This investigation also confirms the rise in IOP in the "responders" previously reported in the treated (Armaly I963, a, b; Becker and Mills r 963) and untreated (Armaly r 966 a, b) eyes, though this rise was less in the untreated eye. 
To explain these significant but paradoxical results, we suggest that a humoral mechanism controls the IOP. A neural reflex for the control of IOP was considered but disregarded, because no significant change was observed in the short-term trial.

There is other evidence to support the idea of the humoral control of IOP:

(I) Lawton Smith, Stempfel, Campell, Hudnell, and Richman (1962) showed that diurnal variation in IOP was closely related to diurnal variation of plasma $\mathrm{I} 7$-hydroxycorticosteroid and that the height of the IOP corresponded to plasma steroid peaks.

(2) Raised IOP in cases of Cushing's syndrome reverted towards normal after the removal of cortisol-producing tumours (Neuner and Dardenne, I 968).

There is also evidence that topically-administered steroids are absorbed in sufficient amounts to produce systemic effects:

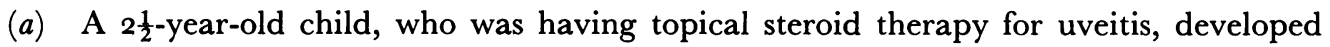
cushingism during treatment (Musson and Sloan, I968).

(b) The topical use of dexamethasone has been shown to cause a reduction in urinary ketosteroids (Burch and Migeon, ig68).

(c) A patient with an allergy to citrus fruit showed an alleviation of the allergic symptoms when topical steroids were instilled into the eye (Nursall, 1965).

A systemic dose of dexamethasone causes a depression in plasma cortisol level. There is evidence that the plasma cortisol depression response differs in the responder and nonresponder groups. Levene and Schwartz (1968) examined plasma cortisol levels before and $24 \mathrm{hrs}$ after an oral dose of $0.75 \mathrm{mg}$. dexamethasone in a series of patients who had previously had steroid provocation tests. Patients with a high rise in ocular pressure rise (i.e. the responders) showed little depression in plasma cortisol, but those with the smallest ocular pressure response (i.e. the non-responders) showed a significant depression in plasma cortisol.

It is likely that the ability of dexamethasone to suppress the plasma cortisol level is genetically determined. Topically administered dexamethasone is absorbed into the general circulation in a concentration sufficient to suppress plasma cortisol levels. In the non-responders this suppression of plasma cortisol may cause a fall in the IOP in the untreated eye, while the direct action of dexamethasone on the treated eye prevents a parallel fall in IOP. In the responders, however, the plasma cortisol level is not suppressed and the direct effect of dexamethasone on the trabecular meshwork causes a rise in IOP in the eye receiving dexamethasone, while the small amount of absorbed dexamethasone combined with the unsuppressed plasma cortisol level also results in a slight rise in the IOP in the untreated eye.

This humoral nature of IOP control and the relationship between the plasma cortisol level and the IOP are now being studied.

\section{Summary}

The effect of short-term and long-term topical dexamethasone was observed in glaucomatous and ocular hypertensive eyes. In the "responder" group in the second series, there was a highly significant rise in the IOP in the treated eye and a smaller but significant rise in the untreated eye. In the "non-responder" group the IOP was lowered in the untreated eye. The mechanism of these different responses are discussed. 
This work was carried out in the Glaucoma Clinic, Moorfields Eye Hospital, under the direction of Mr. Redmond J. H. Smith, to whom our thanks are due. We are also indebted to Mr. Redmond Smith and Mr. R. F. Fisher for their helpful criticism in the preparation of this paper.

\section{References}

ARmaly, м. F. (1963 a) Arch. Ophthal. (Chicago), 70, 682

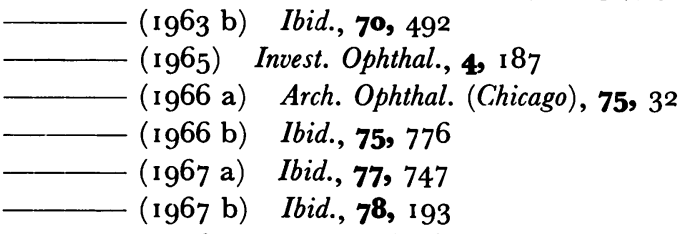

BECKER, B., and MILLS, D. W. (1963) Ibid., 70, 500

BURGH, P. G., and MIGEON, C. J. (1968) Ibid., 79, 174

FRAnçors, J. (1954) Ann. Oculist (Paris), 187, 805

goldmann, H. (1962) Arch. Ophthal. (Chicago), 68, 62 I

LEVENE, R. Z. and SCHWARTZ, B. (1968) Ibid., 80, 46 I

- - Wigdor, A., edelstein, A., and baum, J. (1967) Ibid., 77, 593

LIEB, w. (1963) Klin. Mbl. Augenheilk., 142, 952

LINNÉR, E. (1959 a) Trans. ophthal. Soc. U.K., 79, 27

- (1959 b) Docum. ophthal. (Den Haag), r3, 2 10

Miller, S. J. H., and PATERSON, G. D., (1962) Brit. J. Ophthal., 46, $5^{1} 3$

MUSSON, K. H., and SLOAN, D. D. (1968) J. pediat. Ophthal., 5, 33

NeUner, H. P., and Dardenne, U. (1968) Klin. Mbl. Augenheilk., 152, 570

NurSall, J. F. (1965) Amer. J. Ophthal., 59, 29

RAMSEll, T. G., TRILlWOOD, w., and DRAPER, G. (1967) $\quad$ Brit. F. Ophthal., 5I, 398

SMith, J. LAWTON, STEMPFEL, R. S., CAMPELl, H. S.. HUDNELl, A B., and RichMAN, D. W. (I962)

Amer. 7. Ophthal., 54, $4 \mathrm{II}$

SPAETH, G. L. (1970) Invest. Ophthal., 9, 73

stern, J. J. (1963) Amer. J. Ophthal., 36, 389 